https://doi.org/10.48009/1_iis_2010_304-308

\title{
AN ANALYSIS OF THE IMPACT OF ELECTRONIC MEDICAL RECORDS SYSTEM IN A GLOBAL MEDICAL TOURISM ENVIRONMENT
}

\author{
Saviour L. S. Nwachukwu, Southern University and A\&M University, saviour_nwachukwu@ subr.edu \\ Mysore Ramaswamy, Southern University and A\&M University, mysore_ramaswamy@subr.edu \\ Ashagre Yigletu, Southern University and A\&M University, ashagre_yigletu@ subr.edu \\ Donald R. Andrews, Southern University and A\&M University, donald_andrews @ subr.edu
}

\begin{abstract}
Currently, whenever EMR and electronic health record systems (HER) are implemented, it is basically within a given healthcare organization or a network of healthcare organizations [12]. The adoption of a standardized (interoperable) electronic medical records system (EMR) and electronic health records $(E H R)$ system will lead to an increase in the capabilities of foreign medical facilities (in developing countries) to attract more medical tourists from developed/industrialized countries. In a global medical tourism environment, a standardized (interoperable) EMR can be utilized to manage patient care across health care systems located across multiple countries.
\end{abstract}

Keywords: Healthcare Information Systems, Organizational Use of Information Systems, Information and Communication Technology

\section{INTRODUCTION}

A health care model has been developing that show great promise for significantly lowering medical costs while providing quality care $[19,21]$. Generally referred to as medical tourism, this business model has been growing in several developing countries over the past decade [21]. Medical Tourism can be defined as [19]:

Planned foreign travel for the purpose of obtaining high-quality, cost effective, nonemergency medical treatment.

The planned travel in many cases includes a vacation/tourist element - hence, the term "medical tourism". The strength of the phenomena rests on the fact that even when vacation/tourism expenses are added to the cost of the medical treatment, the total amount is generally far less than the cost of domestic medical care alone - particularly, for medical tourists from the United States.
Presently, in the United States, there is significant push towards electronic medical records. Through the health care information exchange that the system promises to provide, health care providers will have access to a longitudinal (historical) medical record of each patient [2].

\section{PURPOSE OF THE PAPER}

This paper presents a literature review of works in both the medical tourism and the electronics medical records areas; it examines the potential impact of the adoption of electronic medical records system in a medical tourism environment. The paper takes a positive approach (as opposed to a normative approach) to the presentation. That is, the paper examines "what is" happening in these two areas, as reported by the works reviewed, and not "what ought to be" happening [11].

\section{MEDICAL TOURISM}

Medical tourism is market driven. Many factors have been identified as contributing to the increase in and popularity of phonomena. These include $[14,16,17$, 19, 21]:

- Affordability of Care - Low Cost (50\% 90\% Savings)

- Timeliness of Care - Avoid Waiting Lines

- Availability of Care - Procedure Not Available in Home Country

- Ease of Global Air Transportation

- Advances in Information Technology - The Internet and Cheap Airfares

- High Quality of Care - Highly Trained Medical Professionals

The global medical tourism market is expected to grow to about $\$ 40$ billion by 2010 [13, 19]; this estimate includes all travel by individuals from all countries for medical treatment abroad. There are 
reports that have estimated that 500,000 Americans travel overseas for medical care each year.

However, research conducted by McKinsey \& Co. (published May 2008) estimates that only about 5,000 to 10,000 Americans are currently seeking care outside the country each year; roughly about one to two percent of the estimates that are generally reported by medical tourism enthusiasts. Nevertheless, there is general agreement that global medical tourism is growing, and the number of Americans traveling abroad for medical care is rapidly growing as well $[8,15,19,21,22]$.

\section{THE POTENTIAL IMPACT OF HEALTHCARE REFORM INS THE U.S.}

Healthcare experts generally agree that current reforms being implemented in the U.S. may lead to the improvement of quality of patient care and reduce the inefficiencies in the system, but, it will not lead to a drastic reduction in current costs [22].

There are those who argue that even if current reforms succeed in reducing medical costs, healthcare providers in the U.S. will still not be able to match the low prices patients can pay for equally good healthcare services in many of the developing countries that offer medical tourism - e.g., Singapore, India, Thailand, Mexico [22]. The major reasons for the high medical costs can be summarized as follows:

"In the U.S. bricks and mortar cost more, drugs and devices cost more, and nurses and physicians are paid more," .... "The U.S. will not in the foreseeable future be able to compete on those issues and close the gap." (Italics added)

[22, quoting Victor Lazzaro Jr., CEO of the medical travel coordinator BridgeHealth International)

\section{CONCERNS REGARDING MEDICAL TOURISM}

There is little debate that traveling abroad for medical treatment provides significant economic savings for many groups, especially the uninsured. However, an issue of debate is whether the medical services being provided by foreign doctors, staff and their medical facilities meet the quality and safety standards that Americans are accustomed to and have come to expect [19].

Volume XI, No. 1, 2010
Critics of medical tourism argue that the quality of care in medical tourism destinations is lower than the quality that patients would normally receive in the United States. However, McCallum and Jacoby [19] argue that, although, travel abroad for medical treatment may indeed involve risks, the risks may not be any greater than what one would expect to encounter in a typical health care settings in the United States and other advanced/industrialized countries [19]. Nevertheless, many medical tourism facilities have taken measures to ensure the quality of care [19]. These measures include:

- qualifications and skills of doctors and other health care professionals

- level of technological sophistication

- comfort of pre- and post-operative care

- condition of facilities

- patient reports of overall satisfaction

In addition, many foreign medical facilities have sought and received certification (accreditation) from the Joint Commission International, the global branch of the Joint Commission, a U.S. institution established to ensure that U.S. hospitals meet specific quality and safety standards $[1,4]$. According to McCalum \& Jacoby [19] there is evidence to indicate that the quality of care at the premier medical tourism facilities is on a par with the quality generally obtained at the average U.S. provider.

However, as healthcare providers in the United States move towards an electronic medical record (EMR) system, there is the question of how foreign medical facilities would participate in a future environment of digitized electronically accessible medical records? Do they recognize the potential impact of a global EMR system on the medical tourism phenomena?

\section{ELECTRONIC MEDICAL RECORD (EMR) IN A MEDICAL TOURISM ENVIRONMENT}

The United States is building a point-of-care health information system to match the worldwide network of electronic banking.

The U.S. healthcare system includes a large number of healthcare providers from which the consumers can choose. There are more than 500,000 officebased physicians, approximately 5,000 community hospitals, more than 16,000 certified nursing facilities, and many other care settings [2]. For Americans who are willing and able to travel abroad, one can add several premier foreign medical facilities to their choice set. 
Choice allows consumers to choose providers based on their proximity, quality and capability, cultural aptitude, or many other factors that may be of concern to any given consumer, including costs and payment plans [2]. However, without some means of integration, choice can lead to fragmentation of the consumer's health care experience. Fragmentation, in turn, results in errors, duplication, lack of coordination, and many other problems [2]. For consumers that receive medical services from both domestic and foreign (medical tourism) health care providers, these factors can easily be compounded.

\section{INTEGRATION THROUGH INFORMATION TECHNOLOGY: ELECTRONIC MEDICAL RECORDS}

Integration mechanisms have been tried in the past; however, most have been in the form of mergers physician roll-ups, specialty carve-outs, and specialty carve-ins [2]. While integration through mergers has been successful to some extent, information as a mechanism for integration presents a much greater promise [2].

Electronic Medical Record (EMR) systems have been available in various forms for more than three decades [5]. Integration of medical information has been contemplated and debated for two decades, but technical barriers have kept it out of reach until recently [23]. It is estimated that currently only about 28 percent of medical doctors in the U.S. have EMR system [23], and with those that do, most of the software systems were not design to communicate with each other, and more specifically, the individual systems do not provide data in a format that can be read by other systems - therefore, they lack interoperability. Generally, current systems were designed and implemented to function as individual information silos. As Richardson [23, p. 1] noted:

Dozens of different software companies have designed programs for the special needs of different health care providers. The programs promise to improve data management, service, profits, and billing practices. However, the main benefit of EMRs - information sharing across health care providers - has been almost completely lost.

This is just with systems developed and marketed by software companies in the United States. To add to the fragmentations and complexities, some of the premier medical facilities that serve as medical tourism destinations have developed their own inhouse electronic medical record systems to manage patient care $[18,19]$. According to Lindsay [18]:

Bumrungrad (a major medical facility in Thailand) replaced its paper records seven years ago with a homegrown, all-digital system, an upgrade U.S. hospitals have struggled with for years, despite the assistance of giants like Cerner, Siemens, and General Electric. (italics added)

The current situation of different electronic medical record systems with little or no interoperability capabilities represent an opportunity for foreign medical facilities as they strive to increase the number of medical tourists that they serve. An effective strategy that they can employ may simply be "Integration":

- Integration of medical services - through the development of alliances with established health care networks and insurers in the U.S. and other advanced/industrialized countries; and

- Integration of medical information through the implementation of electronic medical record systems with interoperability capabilities.

\section{Integrated Global Healthcare Alliances}

Global healthcare alliances are beginning to emerge. Renowned U.S. medical schools such as Harvard and Johns Hopkins have open dozens of hospitals and teaching programs abroad. For example, Harvard has partnerships in Mumbai, Seoul, Istanbul, Xinjiang, and Islamabad; however, its most enterprising venture is Dubai Healthcare City, a state-of-the-art complex staffed with the best equipment and doctors [18].

A few businesses and health care plans are beginning to offer their employees the option of traveling abroad for medical services [1, 10]. For example, Hannaford Bros. Co. (a super market chain in the northeastern area of the U.S.) announced in 2008 that it would explore the possibility of sending its employees to Singapore for knee and hip replacements to save the company money [25]. Blue Cross \& Blue Shield of South Carolina has developed alliances, through its Companion Global Healthcare subsidiary, with Bumrungrad International Hospital 
(Bangkok), Parkway Group Healthcare (owner of three hospitals in Singapore), and hospitals in Turkey, Ireland, and Costa Rica [20].

\section{Integrated Global Electronic Medical Record Systems}

A major strategy that will probably lead to the greatest impact on the growth of medical tourism is integration through information technology specifically, electronic medical records (EMR) system with interoperability capabilities.

The goal of an EMR system is to convert medical records from paper charts to digital electronic charts, thereby enhancing the flow of patients' information to all who might be involved in the patients care[9]. According to Feld [9], an electronic medical record (EMR) is only one component; the system that is actually needed is an electronic health record (EHR), with multiple components. An electronic health record (EHR) is a personal medical record (EMR) that can be accessed (globally) over a network (e.g., Internet).

It is argued that through health care information exchange and interoperability (HIEI), healthcare providers everywhere (globally) can have access to a longitudinal (historical) medical record with full information about each patient [2, 24]. The technology will make it possible for every medical professional any where in the world, to seamlessly access information about any patient in their care.

Consumers will have better information about their health status since personal health records and similar access strategies can be feasible in an interoperable environment. In addition, consumers will be able to move more easily between and among healthcare providers (globally) with the confidence that each doctor and facility has access to the same information $[2,24]$.

Similar to the global electronic banking network which makes it possible for all businesses (big and small) across the globe to instantly access customers' credit information, an electronic medical records and individual health records system will provide instantaneous access to valuable health care information. In addition to the benefits of information sharing, an EMR system provides significant improvements in many areas of a typical medical organization, including reduction of administrative and clerical costs, improvement in administrative efficiency, and improvement in the efficiency of clinicians thereby increasing the quality of patient care and services $[3,5,6,7]$.

\section{CONCLUSIONS}

Currently, whenever EMR and EHR are implemented, it is basically within a given healthcare organization or a network of healthcare organizations [12]. The adoption of a standardized (interoperable) electronic medical records system (EMR) and electronic health records (EHR) system will lead to an increase in the capabilities of foreign medical facilities (in developing countries) to attract more medical tourists from developed/industrialized countries.

In a medical tourism environment, a standardized (interoperable) EMR can be utilized to manage patient care across hospital systems located across multiple countries.

\section{REFERENCES}

1. Bernhart, Molly (2008). Taking Off. Employee Benefits Adviser, July, pp. 22-30.

2. Brailer, David (2005). Interoperability: The Key To Future Health Care System. Health Affairs, 19 January. Retrieved November 15, 2009 from http://content.healthaffairs.org/cgi/content/fu 11/hlthaff.w5.19/DC1

3. Bright, Beckey (2007). Benefits of Electronic Health Records Seen As Outweighing Privacy Risks. The Wall Street Journal Online, November 27. Retrieved November 15, 2009 from http://online.wsj.com/article/SB1195652442 62500549.html

4. Camarow, Avery (2008). Under the Knife in Bangalore. U.S. News \& World Report, May 12, Vol. 144 Issue 13, pp. 42-50

5. Chismar, William G. and Sean M. Thomas (2004). The Economics of Integrated Electronic Medical Record Systems. In M. Fieschi, E. Coiera and Y.-C.J. Li (Editors) MEDINFO 2004 - Proceedings of the 11th World Congress on Medical Informatics, pp. 592-596,

6. Clayson, Edward T. (2009). Medical Communications for Casualty Care (MC4): The Hidden Benefits of Electronic Medical 
Records. Defense AT\&L, January-February, pp. 60-61.

7. Congressional Budget Office. (2008). Evidence on the Costs and Benefits of Health Information Technology: A CBO Paper (CBO Publication No. 2976). Washington, DC: U.S. Government Printing Office. Retrieved November 15, 2009 from http://www.cbo.gov/ftpdocs/91xx/doc9168/0 5-20-HealthIT.pdf

8. Dunn, Philip (2007). Medical Tourism Takes Flight: With High Quality, Low-Cost Care, Overseas Hospitals Hope to Turn a Trickle of US Patients into a Trend. $H \& H N$, November, pp. 40-44.

9. Feld, Stanley (2006). The Complexity of the EMR Issue. Retrieved November 15, 2009 from http://stanleyfeldmdmace.typepad.com/repai ring_the_healthcare_/ 2007/01/the_complexity_.html

10. Forgione, Dana A. \& Pamela C. Smith (2007). Medical Tourism and Its Impact on the US Health Care System. Journal of Health Care Finance, 34(1), pp. 27-35.

11. Milton, Friedman (1966). The Methodology of Positive Economics. In Essays In Positive Economics, Chicago: Univ. of Chicago Press, pp. 3-16, 30-43.

12. Halamka, John D. (2005). Health Care's Sore Need for Standards. ComputerWorld, October 24, p. 19

13. Hancock, D. (2006). The Complete Medical Tourist: Your Guide to Inexpensive and Safe Cosmetic, Medical, and Dental Surgery Overseas. London: John Blake Publishing, Ltd.

14. Hansen, Fred (2008). A Revolution in Heathcare: Medicine Meets the Marketplace. IPA Review, January, pp. 4345

15. Horowitz, Michael D. (2008). Why in the World Do Patients Travel for Medical Care? Asia Pacific Biotech News, Vol. 12 Issue 7, p24-28.
16. Horowitz, Michael D. and Jeffrey A. Ronsensweig (2007). Medical Tourism Health Care in the Global Economy. The Physician Executive, November-December, pp. 24-30.

17. Koster, Kathleen (2009). Spurred by Economy, Medical Tourism Poised for Breakout in '09. Employee Medical News, February, p. 38

18. Lindsay, Greg (2008). Medical Leave. Fast Company, May, Issue 125, pp. 108-119

19. McCalum, Brent T. and Philip F. Jacoby (2009). Medical Outsourcing: Reducing the Clients' Health Care Risks. Benefits \& Compensation Digest, pp. 26-32.

20. Miller, Richard K. and Kelli Washington (2010). Chapter 33: Medical Tourism. The 2010 Healthcare Business Market Research Handbook, 14 ${ }^{\text {th }}$ Edition, p75-77, U.S.A.: Richard K Miller \& Associates

21. Ozan-Rafferty, Maggie (2009). Engaging Patients in a Global Market. Gallup Management Journal Online, December 17, p. 1

22. Rhea, Shawn (2009). Still Packing Their Bags. Modern Health, July 27, Vol. 39 Issue 30, pp. 28-30.

23. Richardson, Craig (2009). Markets and Medical Records. AIER Research Reports, Vol. LXXVI (No. 15), September 7.

24. Walker, Jan, Eric Pan, Douglas Johnston, Julia Adler-Milstein, David W. Bates, and Blackford Middleton (2005). The Value of Health Care Information Exchange and Interoperability. Health Affairs, 19 January. Retrieved November 15, 2009 from http://content.healthaffairs.org/cgi/content/fu 11/hlthaff.w5.10/DC1

25. Wojik, Joanne (2009). Employers Considering Short-Haul Medical Tourism. Business Insurance, Vol. 43 Issue 29, pp. 120. 